Grand Valley State University

ScholarWorks@GVSU

2012

\title{
Americanization of Web-Based Political Communication?: A Comparative Analysis of Political Blogospheres in the United States, the United Kingdom, and Germany
}

Ki Deuk Hyun

Grand Valley State University, hyunk@gvsu.edu

Follow this and additional works at: https://scholarworks.gvsu.edu/com_articles

Part of the Communication Commons

\section{ScholarWorks Citation}

Deuk Hyun, Ki, "Americanization of Web-Based Political Communication?: A Comparative Analysis of Political Blogospheres in the United States, the United Kingdom, and Germany" (2012). Peer Reviewed Articles. 9.

https://scholarworks.gvsu.edu/com_articles/9

This Article is brought to you for free and open access by the School of Communications at ScholarWorks@GVSU. It has been accepted for inclusion in Peer Reviewed Articles by an authorized administrator of ScholarWorks@GVSU.For more information, please contact scholarworks@gvsu.edu. 


\title{
Americanization of \\ Web-Based Political \\ Communication? A \\ Comparative Analysis \\ of Political Blogospheres \\ in the United States, \\ the United Kingdom, \\ and Germany
}

Journalism \& Mass Communication Quarterly

89(3) 397-4I3

(C) 2012 AEJMC

Reprints and permission: sagepub.com/journalsPermissions.nav DOI: 10.1 I77/1077699012447919 http://jmcq.sagepub.com

@SAGE

\section{Ki Deuk Hyun'}

\begin{abstract}
Political blogging provides a useful testing ground for the thesis of Americanization effects of new media technology that emerged in the United States and spread internationally. This study examined the network of hypertext links to top political blogs in the United States, the United Kingdom, and Germany. The U.S. blogging network showed higher interconnectedness than did the U.K. and German networks, and was more highly fragmented along the lines of political differences. This study presents the relationships among the new communication form, its international diffusion, and the role of indigenous conditions affecting its adoption.
\end{abstract}

\section{Keywords}

comparative analysis, network analysis, new media technology, political blog, political communication culture

New media technology has generated sharp debates about its power to disrupt existing relations and structures in national and international communication. Given this transformative potential, two major themes stand out in the current discussion. First, due to

'Grand Valley State University, Allendale, MI, USA

Corresponding Author:

Ki Deuk Hyun, School of Communications, Grand Valley State University, I Campus Drive, Allendale, MI 4940I-940I, USA

Email: kideuk.hyun@gmail.com 
its border-crossing capability, new technology is considered a driving force behind the Americanization, or global convergence, of the media, steering them toward the form and practice originating in the United States. Others oppose this homogenization scenario, arguing that the transnational diffusion of culture and media is a process of interaction between the local and the foreign. They emphasize the active role of indigenous cultures and systems in reshaping imported forms and integrating them with already existing practices to meet their own national needs. ${ }^{1}$ Second, the decentralizing features of new media technology, represented by the Internet, have raised expectations that it may undermine elite dominance in traditional communication platforms and revitalize the public sphere for citizen deliberation and participation. ${ }^{2}$

Political blogging provides a useful testing ground for these arguments because it emerged and is popularized as a citizen-based alternative to U.S.-institutionalized media, and subsequently spread internationally. Discourse about political blogs, however, is largely centered in the United States, causing theoretical concerns about either false generalizations that extend the idiosyncratic experience of an individual country to others or, conversely, false particularizations that misinterpret the common experience as particular. ${ }^{3}$ To address that limitation, this study compares the political blogging communities of the United States, the United Kingdom, and Germany.

The current research considered not only cross-national commonalities and national particularities, but also the democratizing effects of new media. Scholars have noted that actor relationships involved in the news production and circulation of traditional media represent domination and subordination in a society, which symbolically supports reproduction of the existing power structure. ${ }^{4}$ Some authors claim political blogging weakens the extant configuration by developing a collectivity of egalitarian and conversational relationships, often called the political blogosphere. ${ }^{5}$

To determine the nature of relationships formed in the political blogosphere, this study employs a social network approach. Because hypertext links, commonly shortened to hyperlinks, function as the chief instruments to signal and maintain communicative relations among bloggers, ${ }^{6}$ this research explores the network structures of hyperlinks formed in the political blogospheres of three countries. Specifically, it examined whether and to what extent the three political blogospheres constitute cohesive, egalitarian, and conversational venues for political discourse through the analysis of (1) network density (the extent to which bloggers are interconnected to each other through hyperlinks), (2) network centralization (the extent to which blogger relations are egalitarian in hyperlink exchange), and (3) network subgroup density (the extent to which bloggers are engaged in crosscutting conversations through hyperlink exchanges with politically opposing bloggers).

\section{Political Communication Cultures and Blogging}

Initial observations indicate the relative prominence of the U.S. blogging community, compared to those of the United Kingdom and Germany. ${ }^{7}$ This unparalleled development seems to relate to structural and cultural factors-political, journalistic, and 
technological —of the three countries. Comparative media studies have explored how these factors affect the form and practice of political communication. Focusing on the relative "discretionary power" or autonomy of the media from state and political institutions, scholars have suggested two distinct cultures of political communication in Western democracies: "mediatized or media-centered culture" and "politicized or party-centered culture." ${ }^{8}$ News media in the mediatized culture function mainly as a mediating zone of competing political interests, relatively distant from the loci of political power. On the other hand, news outlets in the politicized culture have aligned their editorial directions with specific political groups and parties.

Although this distinction is not a clear-cut dichotomy, and a transnational trend toward a media-centered culture has been noted, comparative scholars have documented the United States as the most mediatized culture, whereas Germany belongs to a politicized alternative, and Great Britain is located between the two. ${ }^{9}$ This study assumes that two different cultures either facilitate or hinder specific patterns of adoption and use of new media for political communication, including political blogs. First, the political system underpinning the mediatized U.S. culture emphasizes greater citizen participation and interaction than does the politicized culture of Germany. This participatory model of democracy values citizen involvement in the whole process of politics, including "agenda-setting, deliberation, legislation, and policy implementation." ${ }^{10}$ On the contrary, the representative model of democracy in Germany stresses the role of political organizations as institutional linkages to competing social groups over direct citizen participation in the political process. ${ }^{11}$

This contrast develops the distinctive attitudes and uses of new media as communicative tools in politics. The "digital democracy" debate in the United States, for example, centers on the potential of new media technology to reinvigorate and implement direct democracy, whereas the debate in Germany revolves around the opportunity new media bring to enhance the efficiency of established political institutions for public relations and internal communication. In this sense, the idea of electronic democracy is an "American exception" associated with a political context in which direct citizen participation is promoted. ${ }^{12}$ Popularizing political blogs in the United States as a new platform for both horizontal and vertical communication, unmediated by institutional media, should be understood within this particular political setting.

Second, the primacy of media logic in a media-centered culture places greater emphasis on the role of the news media in the public sphere. A mediatized culture cultivates a pragmatic journalistic culture in which journalists make their news judgments according to professional or organizational goals. In a politicized culture, journalists are more likely to take sacerdotal attitudes representing the goals and perspectives of political institutions. ${ }^{13}$ Consequently, the perception of powerful media breeds greater concerns about media performance in the media-centered culture, relative to the party-centered culture. In the United States, journalism and the media in general are often singled out as the main villains in the crisis of participatory democracy. ${ }^{14}$ Accordingly, public trust in media institutions is lower in the United States, compared with Western European countries belonging to politicized cultures. ${ }^{15}$ 
Academic and popular discourses thrive in the United States regarding alternatives to the mainstream media, such as public journalism. ${ }^{16}$ Against this backdrop, political blogging in the United States is claimed to be a new form of citizen journalism challenging the "corrupted" mainstream media. ${ }^{17}$

Third, the different technocultural histories of the three countries develop distinctive expectations about the role of new media technology in political communication. Hagen contrasts technological optimism in the United States and technological pessimism in Germany. Since the beginning of the United States, he argues, technology has been considered an instrument for democracy and freedom. The country's Founding Fathers understood "the creation of the republic as the creation of a government technology." 18 On the contrary, Hagen continues, the German public maintains suspicion about media technology that served the Nazi dictatorship as a device of propaganda and control. Therefore, he concludes, Americans anticipate a more active role from new media as a "technological fix" to problems arising from current political and media systems.

On the other hand, the political and media culture of Great Britain reveals mixed characteristics of both the U.S. mediatized and German politicized cultures. Politically, Great Britain has a multiparty system like other Western European countries, but its politics is organized around the two major centrist parties, as is U.S. politics. Ideologically, Great Britain's left-right political spectrum is relatively narrow, showing the least support for extremist parties, such as communist and far-right parties, among the Western European countries. ${ }^{19}$

Regarding media culture, Great Britain has developed forms and practices similar to those found in America, and they are therefore often grouped together as an "AngloAmerican" or a "liberal" model of journalism, which emphasizes journalistic neutrality and fact-oriented reporting style. However, like German newspapers, British newspapers tend to have partisan ties with specific political parties in their editorial positions and readership bases, which distinguishes themselves from the U.S. press. ${ }^{20}$ British intermediary culture is observed in the development of political blogging. Although U.K. political blogging started later than its American counterpart, it began to integrate into an important element of the emerging "political information process" involving both traditional and new media. ${ }^{21}$ The growing influence of British political blogging in political communication contrasts with the relatively slow growth of the German political blogosphere, which some have observed as still being "under construction." 22

\section{Political Blogging as Community}

One major consequence of the popularization of political blogging in the mediatized United States, and to a lesser degree in the United Kingdom, is that it could foster the emergence of shared identity among bloggers. A strong blogging community helps facilitate the differentiation of political blogging as a new subsystem of political communication. Political blogging is attaining the status of a "budding occupation 
community" in which members share the norms and values of doing similar activities. ${ }^{23}$ Shared identity develops when members inside a specific communal boundary admit particular organizational characteristics and those outside recognize the legitimacy of those properties. ${ }^{24}$ Anecdotal observations indicate that in the United States, political blogging has achieved considerable inside-community identity and outsidecommunity recognition of its legitimacy. For instance, there are many blogging conferences and symposia, discussions of norms and values about political blogging are abundant, bloggers have been granted some legal protections, and politicians and the media have begun to accept the unique function of blogs. ${ }^{25}$ As a networked community, U.S. political bloggers undermine dominance by the mainstream news media in the agenda-setting process. ${ }^{26}$ This identity distinguishing bloggers from other communication actors is predicted to lead to greater interaction among its members, which should manifest itself in dense interconnection among its members in a network.

H1: The U.S. political blogging network will show a higher density than the British and German political blogging networks.

\section{Political Homophily and Blogging}

Social scientists have uncovered the general human tendency to establish social and communicative relations on the basis of the similarity of key attributes among social actors, a predisposition known as homophily. Such inclination increases the efficiency of communication, fostering trust and mutuality in social exchange and interaction. ${ }^{27}$ This homophily tendency was found to cause fragmentation of the U.S. blogosphere along the bloggers' political differences. ${ }^{28}$ Since homophily is a general human predisposition, political bloggers of the three countries are expected to make more hyperlinks to politically like-minded bloggers than those having opposing orientations.

H2: Within-subgroup density will be greater than between-subgroup density across the three countries' blogging networks.

Although homophily is taken as a norm in making social and communicative ties, the nature of social fabrics in particular countries also affects the extent to which different groups interact with each other. Both political and media factors in the United States might shape their political blogging networks as mainly partisan venues. The twoparty majoritarian system of the United States makes political distinctions between the governing and the opposition party much easier than in the multiparty consensus systems of European countries. ${ }^{29}$ Because the winning party monopolizes power in a majoritarian system, the political stakes of electoral outcomes would be greater than in consensus systems like that of Germany, where governance by power sharing is common in the form of coalition.

Sharp political rivalries in two-party majoritarian politics, therefore, are likely to increase the need for homophily in communication to avoid psychological and social 
discomfort. In fact, Americans are less likely to engage in political talks with those holding opposing political views as compared to people from other countries, including Great Britain and Germany ${ }^{30}$ In addition, the objectivity model of journalism, assuming the news media as neutral mediators, flourishes in mediatized cultures like that of the United States. This information-oriented journalism culture leaves a media niche for highly partisan and opinionated expressions outside the mainstream media, ready for political blogging to fill. ${ }^{31}$ Based on these political and media factors specific to the United States, the third hypothesis predicts,

H3: Within-subgroup density will be greater in the U.S. political blogging network than in the British and German political blogging networks.

\section{Equality in the Political Blogging Community}

The size and duration of a community accelerates the process of hierarchization among its members. When a network has many members, it is almost impossible for those who belong to evaluate each other's qualities through direct contact and interaction. Therefore, an individual's judgment about a specific actor greatly relies on social cues from the others, which amplifies status differences among community members. ${ }^{32}$ On the web and in the blogosphere, a similar tendency has been observed in the so-called "power law" distribution of incoming links, with very few sites receiving huge numbers of incoming links and most having only a few. The length of time accelerates this inequality in attracting incoming links. As a network grows over time, the older sites get disproportionally more chances of being linked to than do newer ones, with the consequence of "the rich getting richer." 33 Because the U.S. blogging network emerged earlier and has more members than the U.K. and German networks, the prediction in the next hypothesis is for greater inequality in the exchange of hyperlinks in the U.S. blogosphere, compared with the two European counterparts.

H4: The U.S. political blogging network will show higher centralization than the British and German political blogging networks.

\section{Method}

This study employed the social network method to analyze network structures of political blogs of the three countries. A network refers to a specific structure, consisting of actors or nodes connected by particular relationships or lines. These relationships can represent various forms of actor interaction, communication, and interdependency, such as kinship, friendship, and exchange of materials, ideas, or emotions. Especially relevant to the present study, network analysis is a useful tool for examining the power relations, stratification, and group formation within a structure through the analysis of asymmetric ties made among actors. ${ }^{34}$ 


\section{Sampling}

To collect the most linked to political blogs of each country, purposive sampling was employed using multiple blog-ranking sites. Wikio News (www.wikio.com), a news and blog aggregator, was the main website for selecting top blogs because it was the only site ranking the political blogs of all three countries. The site updates the top 100 political blogs of each country monthly, based on the number of incoming links each blog receives from other blogs. This study used the November 2008 rankings, comparing them with those from other blog-ranking sites to check reliability. Although no perfect match was found, there was considerable correspondence among the rankings of these sites. For instance, the same eight U.S. blogs made top-ten lists on both wikio. com and technorati.com, another well-known ranking site. Because wikio.com, like others, missed some top bloggers included in other ranking sites, the researcher checked the political blog rankings of technorati.com and truthlaidbear.com down to the top 30, adding 13 blogs ranked in either of the two sites but excluded in wikio. com. After removing seven blogs from the original wikio.com ranking of incomplete archives, 106 U.S. political blogs were ultimately selected.

A similar sampling strategy was used to select the U.K. and German political blogs. Because no other website provided an extensive ranking list for U.K. political blogs, British bloggers' online voting for top political blogs complemented British Wikio News (wikio.co.uk). ${ }^{35}$ In the case of Germany, two additional blog-ranking sites other than German Wikio News (wikio.de) were identified: topblogs.de and bloggeramt.de. Because network measures are highly sensitive to the number of nodes in a network, the quantities of blogs in the three countries were made equal for cross-national comparability. Consequently, additional British and German blogs were added from the complementary sampling sources to produce the same number of $106 \mathrm{blogs}$, yielding a total of 318 blogs combined. ${ }^{36}$

The time frame for sampling was two randomly selected constructed weeks from 2008. Because political blogging generally operates as an activity following and reacting to the daily news cycle, this method, which is the most efficient for sampling daily newspapers, was chosen. ${ }^{37}$ Archived blog posts from the sampled days were used to obtain hyperlinks for the network analysis. This study analyzed hyperlinks, appearing within posts of each blog and directed to the other 105 blogs in the sample.

Coding. Each blog was coded in terms of its political orientation and organizational affiliation. Organizational affiliation was decided based on the presence and absence of bloggers' official ties with specific organizations, with four broad categories: (1) citizen, (2) news media-affiliated, (3) political party-affiliated, and (4) other. Citizen blogs were those having no official ties with any established organizational entities, whereas news-media-affiliated blogs referred to in-house blogs of traditional and online-only news media. Political-party-affiliated blogs were those with official connections to party organizations or politicians. The category of "other" was reserved for blogs having official relationships with other forms of social organizations. 
Political orientation of the blog was determined according to the blogger's selfclaimed political or party affiliation. When self-claimed identification was not available on the blog, coders examined blog rolls designating bloggers' political orientations and the bloggers' political stands appearing in their posts. The decision was based on their (1) support of specific parties and programs (e.g., support of the Greens of Germany and their proenvironment party program), (2) support of specific politicians and their policy stands (e.g., support of a U.S. presidential candidate - either Barack Obama or John McCain - and his issue positions), and (3) support of a broad left-right political ideology (e.g., support of state intervention in the market).

Different party systems were also considered: the two-party system of the United States versus the multiparty systems of Germany and the United Kingdom. Categorizations for the political orientations of U.S. bloggers were (1) political left, (2) political right, and (3) nonaligned. In Great Britain, the Labour Party and the Conservative Party represent the left-right ideology of British politics, respectively. Because the third party, the Liberal Democrats (Lib Dems), occupies a relatively independent presence both in British parliament and in the blog sample for this study, it was classified as a separate category. Therefore, categorizations for U.K. bloggers were (1) political left, (2) political right, (3) Lib Dems, and (4) nonaligned. In Germany, the political spectrum is much wider than in U.S. and U.K. politics, having a broader range from far-left to far-right groups. Therefore, German bloggers' political orientations were classified according to their party affiliation, such as the Christian Democratic Union (CDU), the Social Democratic Party (SPD), the Free Democratic Party (FDP), the Greens, or the Left Party (PDS). This classification of bloggers' political orientation was used to test $\mathbf{H} \mathbf{2}$ to demonstrate the different natures of political party configurations and their relations to the composition of political blogospheres of the three countries.

For the test of $\mathbf{H 3}$, bloggers' political orientations were reduced to either political right or political left, considering the party coalition patterns in the two European countries. Although the two European countries have multiparty systems, mainstream parties and their coalitions dominate both politics and blogospheres. Thus, those blogs either having no clear political leanings or representing minor-party perspectives outside the mainstream politics of each country, such as far-left or far-right groups, were excluded. After this process, the forty most linked to blogs were selected, representing the two mainstream political orientations of each country: political right and political left.

Two coders examined the U.S. blogs. Scott's pi coefficient was .92 for political orientation and 1.0 for organizational affiliation. Two U.S. graduate students fluent in German and majoring in German studies coded all the German blogs. Scott's pi was .89 for political affiliation and .96 for organizational affiliation. To determine political orientations of the U.K. blogs, the researcher used a British blogger directory listing bloggers' political affiliations. ${ }^{38}$ Two coders checked the organizational affiliations, and Scott's pi was .96 . 
Network analysis. Each political blog was regarded as a node, and a hyperlink appearing within every blog post as a line. A total of 11,188 posts were explored for the U.S. network, 3,764 for the U.K. network, and 2,405 for the German network. The network software program UCINET 6 was used to compute density for H1, subgroup density for $\mathbf{H} \mathbf{2}$ and $\mathbf{H 3}$, and centralization for $\mathbf{H 4} .^{39}$ Density is an index to measure average tie strength among nodes in a network, or the extent to which nodes are connected to one another. Similarly, subgroup density refers to the average tie strength present in predefined subgroups of nodes in a network. In this study, subgroups were determined according to categories used to code blogs' political orientations and subgroup density measured the extent to which bloggers link to both other politically like-minded blogs (within-subgroup density) and politically different blogs (betweensubgroup density). Last, centralization measures the overall equality of relations among nodes, or the extent to which only a few nodes are central or prominent among all nodes in a given network.

\section{Results}

Before comparing network structures, political and organizational affiliations of the blogs were examined. First, the U.S. blogosphere reflected the characteristics of a two-party system, while at the same time a mediatized culture with a relatively strong presence of media-affiliated blogs. In terms of political orientations, conservative blogs were the most common $(n=55)$, followed by liberal $(n=27)$ and nonaligned blogs $(n=24)$. A majority of nonaligned blogs was media affiliated $(n=20)$, such as The Caucus of the New York Times. Organizationally, citizen blogs were the dominant type $(n=75)$, while the rest were affiliated with either news media $(n=28)$ or other organizations $(n=3)$. The selected blogs made a total of 2,759 hyperlinks to each other and received 25.8 links on average $(S D=38.5)$. The five most linked to blogs were Hot Air $(n=201)$, Huffington Post $(n=177)$, Talking Points Memo $(n=166)$, Daily Kos $(n=135)$, and Ben Smith blogging for Politico $(n=117)$.

U.K. political blogs represented a right-left spectrum of British politics: political right $(n=44)$, political left $(n=39)$, and Lib Dems $(n=7)$. The remaining blogs $(n=16)$ were politically nonaligned. In organizational affiliations, citizen blogs were the most common $(n=81)$, followed by political-party-affiliated blogs $(\mathrm{n}=13)$, news-mediaaffiliated blogs $(n=11)$, and other $(n=1)$. A total of 482 hyperlinks occurred in the network, and the U.K. blogs averaged 4.51 incoming links $(S D=6.76)$. The five most linked to blogs were Iain Dale $(n=48)$, Conservative Home $(n=32)$, Guy Fawkes $(n=25)$, LibDem Voice $(n=18)$, and Spectator Coffee House $(n=18)$.

Last, the German blogosphere mirrored its multiparty system, with blogs of such diverse political orientations as SPD $(n=17), \operatorname{FDP}(n=10)$, Green Party $(n=10)$, PDS $(n=4), \mathrm{CDU}(n=3)$, and other minor parties $(n=4)$. Some blogs without self-claimed party affiliations leaned toward the right $(n=9)$ or left side of German politics $(n=10)$, and others were politically uncommitted $(n=39)$. Organizationally, citizen blogs were 
Table I. Subgroup Density of U.S. Political Blogs by Political Orientation

\begin{tabular}{lccc}
\hline & Right & Left & Nonaligned \\
\hline Right $(n=55)$ & $\mathbf{3 2 1}$ & .135 & .222 \\
Left $(n=27)$ & .034 & .838 & .403 \\
Nonaligned $(n=24)$ & .070 & .164 & .348 \\
\hline
\end{tabular}

Subgroup density higher than overall density (.246) in bold.

most common $(n=72)$, but blogs affiliated with political parties also had a relatively strong presence $(n=25)$, apparently reflecting the German politicized culture. The rest belonged to either news media $(n=5)$ or other types of organizations $(n=4)$. German bloggers made a total of 128 hyperlinks and attracted 1.21 links $(S D=2.32)$ on average. Only three blogs had more than five incoming links: Netzpolitik $(n=17)$, Nach Denk Seiten $(n=12)$, and Red Blog $(n=6)$.

H1 predicted that the U.S. blogging network would have a greater density than the British and German blogging networks, reflecting a greater sense of community identity among bloggers. As expected, the U.S. network had the greatest density (.246), which meant an average of .246 ties made for every possible pair of blogs in the network. Density of the U.K. network was .043, whereas density of the German network was $.012 .{ }^{40}$ Because the higher densities of the U.S. network might reflect more frequent posts of American blogs $(n=11,188)$ than those of British $(n=3,764)$ or German blogs $(n=2,405)$, the average number of hyperlinks made by the three countries' blogs was compared. Accounting for differences in the total number of posts, American bloggers still made more hyperlinks per post (.247) than either the British (.128) or German bloggers (.053). H1 was supported.

H2 predicted that within-subgroup density would be higher than the between-subgroup density across the three countries. Supporting the hypothesis, bloggers of the three countries generally made more hyperlinks to politically like-minded bloggers than to bloggers from competing groups. Table 1 summarizes subgroup densities of the U.S. network from the subgroups of political blogs in row positions to those in the column positions. Using density of the overall U.S. network (.246) as a cutting point to decide the presence or absence of subgroup relationships, density values tended to be higher along the diagonal, which meant that across all groups there was a greater tendency toward within-group connections than between-group ties. A similar tendency toward political homophily in making hyperlinks emerged in both the U.K. (see Table 2) and German blogospheres (see Table 3). ${ }^{41}$

H3 predicted that the U.S. network would show the greatest within-subgroup density among the networks of the three countries. Because there is no direct test in network analysis comparing the subgroup densities across different networks, the researcher compared the ratios of the within-group to between-group densities by dividing the former by the latter for each blogging network. For cross-national comparability, the forty most linked to blogs were selected, representing the two broad 
Table 2. Subgroup Density of U.K. Political Blogs by Political Orientation

\begin{tabular}{lcccc}
\hline & Right & Left & Liberal Democrats & Nonaligned \\
\hline Right $(n=44)$ & .087 & .032 & .032 & .026 \\
Left $(n=39)$ & .013 & .044 & .040 & .034 \\
Liberal Democrats $(n=7)$ & .010 & .055 & .381 & .036 \\
Nonaligned $(n=16)$ & .045 & .030 & .071 & .096
\end{tabular}

Subgroup density higher than overall density $(.043)$ in bold.

Table 3. Subgroup Density of German Political Blogs by Political Orientation

\begin{tabular}{lccccccccc}
\hline & CDU & SPD & FDP & Green & PDS & Right & Left & Other & Nonaligned \\
\hline CDU $(n=3)$ & .167 & .039 & .067 & .033 & .000 & .037 & .000 & .000 & .017 \\
SPD $(n=17)$ & .000 & .040 & .000 & .006 & .000 & .013 & .000 & .000 & .006 \\
FDP $(n=10)$ & .067 & .000 & .056 & .020 & .000 & .000 & .010 & .000 & .003 \\
Green $(n=10)$ & .000 & .000 & .000 & .078 & .000 & .000 & .000 & .000 & .013 \\
PDS $(n=4)$ & .000 & .000 & .000 & .000 & .167 & .000 & .050 & .000 & .006 \\
Right $(n=9)$ & .000 & .000 & .000 & .000 & .000 & .069 & .011 & .028 & .009 \\
Left $(n=10)$ & .000 & .000 & .000 & .000 & .025 & .000 & .233 & .000 & .036 \\
Other $(n=4)$ & .000 & .000 & .000 & .000 & .000 & .000 & .025 & .000 & .000 \\
Nonaligned $(n=39)$ & .009 & .002 & .000 & .003 & .013 & .003 & .021 & .026 & .005 \\
\hline
\end{tabular}

Subgroup density higher than overall density $(.012)$ in bold.

political orientations in each country: political right and political left. U.S. blogs on average had the highest ratio of linking to their own political group than to others (8.49), German blogs had the lowest ratio (2.83), and again U.K. blogs were in the middle (3.07). $\mathbf{H 3}$ was supported.

Finally, $\mathbf{H} 4$ predicted that the U.S. political blogging network would show greater centralization and less equality than the British and German blogging networks. Centralization scores range from 0 if all 106 blogs in a network had the same number of incoming links, to 1 if one dominant blog attracted all incoming links and the remaining 105 blogs received no incoming links at all. All three networks showed considerably high levels of centralization, indicating that a small number of blogs attracted most of the hyperlinks. The German network had the highest centralization (.938), followed by the U.K. (.915) and U.S. networks (.878), although the differences were relatively small. $\mathbf{H} 4$ was rejected. ${ }^{42}$

\section{Discussion}

This cross-national comparison of political blogging networks illuminates the relationships among a new communication form, its international diffusion, and the role 
of indigenous conditions affecting the adoption of the new form. One major theme in international communication has been the hegemony of the U.S. media and the transnational homogenization of communication practices and cultures as a consequence. New media technology intensifies this Americanization fear because of its deterritorializing potential when moving across national borders. Indeed, blogging originated in the United States and spread to the United Kingdom and Germany. Findings of the current research, however, suggest that systems and cultures particular to individual nations relate to different patterns of the adoption and use of the new form, although they do not concretely identify a causal relationship.

Political systems and journalism cultures in the United States, and to a lesser degree in the United Kingdom, might provide more fertile ground for political blogging than in Germany. Emphasis on direct citizen participation in the United States can nurture a culture of technology-aided "self-publishing" like political blogging for both citizencitizen and citizen-government interactions. Popularization of blogging in the United States is expected to facilitate the differentiation of blogging as a subsystem of political communication from the media and political party communication, with a subsequent rise in inside-community identity shared by bloggers. The present study supports this argument by showing that U.S. political bloggers make more hyperlinks to each other than do bloggers of the two European countries.

In addition, the institutional linkage between news media and governing institutions, distinguished as a mediatized and politicized culture, was related to the practice of blogging across countries. The mediatized culture involves more autonomous and interventionist media actors in the public sphere, relative to the party-oriented culture. The distance between the press and political power manifested in the objectivity model of journalism might create a bigger media niche for highly opinionated and partisan expression in the United States than in the United Kingdom and Germany. This research provides evidence that American bloggers have a stronger tendency to make hyperlinks to politically like-minded bloggers, making the U.S. blogosphere a zone clearly more isolated along political differences than its U.K. and German counterparts.

In sum, the results indicate that national particularities of the three countries have continued relevance for explaining differences in political blogging activity. They support the view that diffusion and adoption of foreign forms and practices is neither a linear nor hierarchical process. As Hallin and Mancini emphasize, "Where European countries have borrowed American innovations, they have done so for reasons rooted in their own economic and political processes, often modifying them in significant ways." ${ }^{43}$ Comparative media research, therefore, should consider the transnational process as a multidimensional one in which national systems and cultures are being reconfigured, but still play a key role in defining local transformations, adoptions, and hybridizations of communication forms and practices. ${ }^{44}$

In addition, the results serve as a reminder to reexamine the argument that new media should democratize relations and structures of political communication. Rather, network features commonly found in the three political blogospheres represent highly 
insulated social networks of politically like-minded people. Also, linking patterns point to the fact that blogospheres are not as egalitarian as expected. These results challenge the popular belief that political blogging would constitute an egalitarian and conversational venue of citizen discussion and deliberation.

Study limitations should be noted. The blogging networks analyzed represent only small portions of those in the three countries. Because the selected political blogs were the most prominent ones in each country, they may not reveal behaviors typical of average blogs. Another limitation is related to the purposive sampling employed in the present study. For cross-network comparability, the same number of blogs was selected from each country, possibly including more British and German blogs that might not qualify as top blogs. Although the researcher attempted to address this problem by performing additional analyses using different sample sizes, those efforts did not completely remove the possibility that sampling method might have affected network measures found in the study. In this respect, the current research is exploratory rather than conclusive. When a more sophisticated sampling strategy is available in future research, taking into account sizes of blogging populations, we might have more compelling evidence regarding the influences of different political communication cultures on the composition of individual countries' blogospheres.

Finally, the timing of this study merits another caution. In 2008, the United States held a presidential election, while the two European countries did not hold comparable elections. The U.S. presidential election might have facilitated both more active blogging and severe partisan division in the U.S. blogosphere. Future research might consider whether a specific political context like elections can affect the activities and network structures of blogs.

\section{Declaration of Conflicting Interests}

The author(s) declared no potential conflicts of interest with respect to the research, authorship, and/or publication of this article.

\section{Funding}

The author(s) received no financial support for the research, authorship, and/or publication of this article.

\section{Notes}

1. Daniel C. Hallin and Paolo Mancini, Comparing Media Systems: Three Models of Media and Politics (New York: Cambridge University Press, 2004); Roland Robertson, "Glocalization: Time-Space and Homogeneity-Heterogeneity," in Global Modernities, ed. Mike Featherstone, Scott M. Lash, and Roland Robertson (London: Sage, 1995), 25-44; John Tomlinson, Cultural Imperialism: A Critical Introduction (London: Continuum, 1991).

2. Bruce Bimber, "The Study of Information Technology and Civic Engagement," Political Communication 17 (October-December 2000): 329-33; Howard Rheingold, The Virtual Community: Homesteading on the Electronic Frontier (New York: HarperCollins, 1993). 
3. Jay G. Blumler and Michael Gurevitch, The Crisis of Public Communication (London: Routledge, 1995).

4. Herbert J. Gans, Deciding What's News: A Study of CBS Evening News, NBC Nightly News, Newsweek and Time (New York: Vintage, 1979); Todd Gitlin, The Whole World Is Watching: Mass Media in the Making and Unmaking of the New Left (Berkeley: University of California Press, 1980); Gaye Tuchman, Making News: A Study in the Construction of Reality (New York: Free Press, 1978).

5. Dan Gillmor, We the Media: Grassroots Journalism by the People, for the People (Sebastopol, CA: O'Reilly Media, 2006); Jay Rosen, "Bloggers vs. Journalists Is Over," PressThink 15 (January 2005), http://archive.pressthink.org/2005/01/21/berk_essy.html.

6. Rebecca Blood, The Weblog Handbook: Practical Advice on Creating and Maintaining Your Blog (Cambridge, MA: Perseus, 2002); Daniel W. Drezner and Henry Farrell, "The Power and Politics of Blogs" (paper, American Political Science Association convention, Chicago, 2004); Stephen D. Reese, Lou Rutigliano, Kideuk Hyun, and Jaekwan Jeong, "Mapping the Blogosphere: Professional and Citizen-Based Media in the Global News Arena," Journalism: Theory, Practice, Criticism 8 (June 2007): 235-61.

7. Steffen Albrecht, Maren Lübcke, and Rasco Hartig-Perschke, "Weblog Campaigning in the German Bundestag Election 2005," Social Science Computer Review 25 (winter 2007): 504-20; Velin Velkov, "To Blog or Not to Blog," Communication World 22 (NovemberDecember 2005): 35-37.

8. Gianpietro Mazzoleni, "Media Logic and Party Logic in Campaign Coverage: The Italian General Election 1983," European Journal of Communication 2 (March 1987): 81-103; Barbara Pfetsch, "Political Communication Culture in the United States and Germany," Harvard International Journal of Press/Politics 6 (winter 2001): 46-67; Holli A. Semetko, Jay G. Blumler, Michael Gurevitch, and David H. Weaver, The Formation of Campaign Agendas: A Comparative Analysis of Party and Media Roles in Recent American and British Elections (Hillsdale, NJ: Lawrence Erlbaum, 1991).

9. Hallin and Mancini, Comparing Media Systems; Barbara Pfetsch, "From Political Culture to Political Communications Culture: A Theoretical Approach to Comparative Analysis," in Comparing Political Communication: Theories, Cases, and Challenges, ed. Frank Esser and Barbara Pfetsch (New York: Cambridge University Press, 2004), 344-66.

10. Benjamin R. Barber, Strong Democracy: Participatory Politics for a New Age (Berkeley: University of California Press, 1984), 151.

11. Myra Marx Ferree, William Anthony Gamson, Jürgen Gerhards, and Dieter Rucht, Shaping Abortion Discourse: Democracy and the Public Sphere in Germany and the United States (New York: Cambridge University Press, 2002).

12. Martin Hagen, "Digital Democracy and Political Systems," in Digital Democracy: Issues of Theory and Practice, ed. Kenneth L. Hacker and Jan A. G. M. van Dijk (London: Sage, 2000), 54-69; Thomas Zittel, "Political Communication and Electronic Democracy: American Exceptionalism or Global Trend?" in Esser and Pfetsch, Comparing Political Communication, 231-50.

13. Frank Esser, "Dimensions of Political News Cultures: Sound Bite and Image Bite News in France, Germany, Great Britain, and the United States," International Journal of Press/ 
Politics 13 (October 2008): 401-28; Mazzoleni, "Media Logic and Party Logic"; Semetko et al., Formation of Campaign Agendas.

14. Joseph N. Cappella and Kathleen Hall Jamieson, Spiral of Cynicism: The Press and the Public Good (New York: Oxford University Press, 1997); Thomas E. Patterson, Out of Order: An Incisive and Boldly Original Critique of America's Political Process (New York: Vintage, 1994); Robert Putnam, Bowling Alone: The Collapse and Revival of American Community (New York: Simon \& Schuster, 2000).

15. Harris Interactive, "Fewer Americans than Europeans Trust in the Media: Press, Radio and TV” (2005), http://www.harrisinteractive.com/harris_poll/index.asp?PID=534.

16. Theodore L. Glasser, ed., The Idea of Public Journalism (New York: Guilford, 1999); Davis Merritt, Public Journalism and Public Life: Why Telling the News Is Not Enough (London: Routledge, 1997).

17. Gillmor, We the Media; Mark Glaser, "Watchblogs Put the Political Press under the Microscope," Online Journalism Review (2004), http://ojr.org/ojr/glaser/1076465317.php.

18. Hagen, "Digital Democracy," 58, emphasis original.

19. Jan-Erik Lane and Svante Ersson, Politics and Society in Western Europe (London: Sage, 1999).

20. Jean K. Chalaby, "Journalism as an Anglo-American Invention: A Comparison of the Development of French and Anglo-American Journalism, 1830s-1920s," European Journal of Communication 11 (September 1996): 303-26; Hallin and Mancini, Comparing Media Systems.

21. Andrew Chadwick, "The Political Information Cycle in a Hybrid News System: The British Prime Minister and the 'Bullygate' Affair," International Journal of Press/Politics 16 (January 2011): 3-29.

22. Albrecht, Lübcke, and Hartig-Perschke, "Weblog Campaigning."

23. Wilson Lowrey, "Mapping the Journalism-Blogging Relationship," Journalism: Theory, Practice, Criticism 7 (November 2006): 477-500.

24. Glenn R. Carroll and Michael T. Hannan, The Demography of Corporations and Industries (Princeton, NJ: Princeton University Press, 2000); David G. McKendrick and Glenn R. Carroll, "On the Genesis of Organizational Forms: Evidence from the Market for Disk Arrays,” Organizational Science 12 (November 2001): 661-82.

25. Lowrey, "Mapping the Journalism-Blogging Relationship."

26. Sharon Meraz, "Using Time Series Analysis to Measure Intermedia Agenda-Setting Influence in Traditional Media and Political Blog Networks," Journalism \& Mass Communication Quarterly 88 (spring 2011): 176-94.

27. Paul F. Lazarsfeld and Robert K. Merton, "Friendship as a Social Process: A Substantive and Methodological Analysis," in Freedom and Control in Modern Society, ed. Morroe Berger (New York: Van Nostrand, 1954), 18-66; Miller McPherson, Lynn Smith-Lovin, and James M. Cook, "Birds of a Feather: Homophily in Social Networks," Annual Review of Sociology 27 (August 2001): 415-44.

28. Lada A. Adamic and Natalie Glance, "The Political Blogosphere and the 2004 U.S. Elections: Divided They Blog," http://nielsen-online.com/downloads/us/buzz/wp_PoliticalBlogosphere_Glance_2004.pdf; Mark Tremayne, Nan Zheng, Jae Kook Lee, and Jaekwan Jeong, "Issue Publics on the Web: Applying Network Theory to the War Blogosphere," 
Journal of Computer-Mediated Communication 12 (November 2006), http://jcmc.indiana. edu/vol12/issue $1 /$ tremayne.html

29. Arend Lijphart, Patterns of Democracy: Government Forms and Performance in ThirtySix Countries (New Haven, CT: Yale University Press, 1999).

30. Diana Carole Mutz, Hearing the Other Side: Deliberative versus Participatory Democracy (New York: Cambridge University Press, 2006).

31. Lowrey, "Mapping the Journalism-Blogging Relationship."

32. Roger V. Gould, "The Origins of Status Hierarchies: A Formal Theory and Empirical Test," American Journal of Sociology 107 (March 2002): 1143-78; Cecilia L. Ridgeway and Kristan Glasgow Erickson, "Creating and Spreading Status Beliefs," American Journal of Sociology 106 (November 2000): 579-615.

33. Albert-László Barabási, Linked: The New Science of Network (Cambridge, MA: Perseus, 2002); Clay Shirky, "Power Laws, Weblogs and Inequality" (2003), http://shirky.com/ writings/powerlaw_weblog.html; Mark Tremayne, "The Web of Context: Applying Network Theory to the Use of Hyperlinks in Journalism on the Web," Journalism \& Mass Communication Quarterly 81 (summer 2004): 237-53.

34. John P. Scott, Social Network Analysis: A Handbook (London: Sage, 1997); Barry Wellman and Stephen D. Berkowitz, eds., Social Structure: Network Approach (Greenwich, CT: JAI, 1998).

35. Iain Dale, Guide to Political Blogging in the UK 2008-2009 (Tunbridge Wells, UK: Politico's Media Limited, 2008).

36. A list of the 318 blogs is available on request.

37. Daniel Riffe, Stephen Lacy, and Frederick G. Fico, Analyzing Media Messages: Using Quantitative Content Analysis in Research (Mahwah, NJ: Lawrence Erlbaum, 2005).

38. Dale, Guide to Political Blogging.

39. Stephen P. Borgatti, Martin G. Everett, and Linton C. Freeman, UCINET 6 for Windows: Software for Social Network Analysis (Needham, MA: Analytic Technology, 2002).

40. Additional analyses were conducted, varying the number of sampled blogs (e.g., top 10, top 20, etc.), to see whether sample sizes affected the result. Across all comparisons, the U.S. network had higher density than the U.K. and German networks. Also, densities of the larger U.S. samples tended to be greater than those of smaller U.K. and German samples. For instance, to reach a similar level of density to all 106 U.S. blogs (.246), the number of U.K. bloggers should be reduced to about the top 20 blogs (.276). Even when reducing the number of German blogs to the top 10, its density (.144) did not reach the level of all 106 U.S. blogs.

41. The German network showed more complex patterns of between-group connections than did the U.S. and U.K. networks, with frequent ties among bloggers who belong to different political groups but share similar political ideologies. For instance, the CDU bloggers and FDP bloggers, belonging to center-of-right political groups on the country's ideological spectrum, had stronger connections to each other than they did to other political groups.

42. To check the potential influence of sample size on this finding, the researcher varied sample sizes and compared their centralization scores. Across all comparisons, the two European networks tended to have higher centralization scores than the U.S. network. 
However, the results require more cautious interpretation. Reducing sample sizes had a greater impact on the U.S. network than on the U.K. and German networks. As the number of samples decreased, the U.S. centralization scores dropped more noticeably than did the other two countries' scores. This result seems to suggest more sampling of the top blogs from the U.S. network compared with the U.K. and German networks. In general, relationships among blogs should become more equal as fewer blogs are included in the sample. However, the two European networks, especially the German network, did not reduce the inequality gap as much as the U.S. network did with the decrease of sample sizes. This pattern indicates that the two European networks had much more inequality among blogs even in the much smaller samples, which implies there are more top blogs, having similar status, in the U.S. sample than in the other two samples. However, this possibility can be tested only when the blogs are sampled in a proportional way relative to the sizes of the blogging populations of the three countries.

43. Daniel C. Hallin and Paolo Mancini, "Americanization, Globalization, and Securalization," in Esser and Pfetsch Comparing Political Communication, 27, 25-44.

44. Tomlinson, Cultural Imperialism; Robertson, "Glocalization.” 